\title{
A cultura do partejar: entre a ancestralidade e a Pós-modernidade
}

\author{
The Culture of the Partner: etween ancestrality and postmodernity \\ La Cultura del Paradero: entre la ancestralidad y la posmodernidad
}

\author{
Cledineia Carvalho Santos ${ }^{1}$
}

\begin{abstract}
Resumo
Este estudo sobre as parteiras e o ato de partejar em tempos pós-modernos visa compreender como as parteiras idosas se percebem no atual contexto visto que a atividade de partejar em casa tem sido cada vez mais substituída pelo atendimento hospitalar. A pesquisa teve como sujeitos duas mulheres parteiras idosas da região do entorno da Comunidade Quilombola de Nova Esperança na zona rural do município de Wenceslau Guimarães Bahia. Essa discussão passa impreterivelmente pelas histórias de vida de duas mulheres idosas que outrora dedicaram suas vidas em prol de outras mulheres de comunidades rurais. Será necessário refletir como se davam as relações entre a gestante e a parteira, durante e pós-parto e de que maneira estas mulheres parteiras se veem atualmente neste novo contexto social e cultural, onde esta prática tem sido cada vez menos solicitada e paralelamente a isto, acontece esquecimento da importância do legado que estas elas construíram ao longo de sua vida. Neste estudo utiliza-se o método narrativo tendo como aporte a técnica da História Oral de Vida por meio de entrevistas abertas gravadas que se constituem como importante mecanismo que possibilita as colaboras falar sobre si, o que torna a pesquisa rica de subjetividades e memória. O artigo será desenvolvido nas categorias Gênero, Identidade, Velhice, Esquecimentos e Pós-modernidades, a partir de teóricos como: Hebert Marcuse (1975); Michael Pollak (1989); Zygmunt Bauman (1997); Joan Scott (1995); Stuart Hall (2014); Grin Debert (2004); Santos (2005); Yuval Harari (2016), dentre outros.
\end{abstract}

Palavras-chave: Parteiras. Velhice. História de vida. Pós-modernidade.

\begin{abstract}
This study on midwives and the act of parting in postmodern times aims to understand how the midwives perceive themselves in the present context since the activity of parting at home has been increasingly replaced by hospital care. The research had with subjects two elderly women in the region surrounding the Quilombola Community of Nova Esperança in the rural area of the municipality of Wenceslau Guimarães Bahia. This discussion passes through the life histories of two elderly women who once devoted their lives to other women in rural communities. It will be necessary to reflect on the relationship between the pregnant woman and the midwife, during and postpartum, and how these midwives are currently seen in this new social and cultural context, where this practice has been less and less demanded and in parallel to this, forgetting the importance of the legacy that they have built throughout their life. In this study, the narrative method is used as a contribution to the Oral History of Life technique through open recorded interviews that constitute an important mechanism that enables the collaborators to talk about themselves, which makes the research rich with subjectivity and memory. The article will be developed in the categories Gender, Identity, Old Age, Forgetfulness and Postmodernities, from theorists such as: Hebert Marcuse (1975); Michael Pollak (1989); Zygmunt Bauman (1997); Joan Scott (1995); Stuart Hall (2014); Grin Debert (2004); Santos (2005); Yuval Harari (2016), among others
\end{abstract}

Keywords: Midwives. Old age. Life's history. Ancestry. Modernity

\section{Resumen}

1 Mestre em Cultura e Sociedade; Universidade Federal da Bahia; Salvador, Bahia, Brasil; keucarvalho@yahoo.com 
Este estudio sobre las parteras y el acto de partenar en tiempos posmodernos tiene como objetivo comprender cómo las parteras ancianas se perciben en el actual contexto, ya que la actividad de paradero en casa ha sido cada vez más sustituida por la atención hospitalaria. La investigación tuvo con sujetos dos mujeres parteras ancianas de la región del entorno de la Comunidad Quilombola de Nueva Esperanza en la zona rural del municipio de Wenceslao Guimarães Bahia. Esta discusión pasa impretadamente por las historias de vida de dos mujeres ancianas que otrora dedicaron sus vidas en favor de otras mujeres de comunidades rurales. ¿Es necesario reflexionar cómo se daban las relaciones entre la gestante y la partera, durante y después del parto y de qué manera estas mujeres parteras se ven actualmente en este nuevo contexto social y cultural, donde esta práctica ha sido cada vez menos solicitada y paralelamente a esto , sucede olvido de la importancia del legado que éstas construyeron a lo largo de su vida. En este estudio se utiliza el método narrativo teniendo como aporte la técnica de la Historia Oral de Vida por medio de entrevistas abiertas grabadas que se constituyen como importante mecanismo que posibilita a las colaboras hablar sobre sí, lo que hace la investigación rica de subjetividades y memoria. El artículo se desarrollará en las categorías Género, Identidad, vejez, olfrios y post-modernidades, a partir de teóricos como: Hebert Marcuse (1975); Michael Pollak (1989); Zygmunt Bauman (1997); Joan Scott (1995); Stuart Hall (2014); Grin Debert (2004); Santos (2005); Yuval Harari (2016), entre otros.

Palabras clave: Parteras. la vejez. Historia de vida. Posmodernidad.

\section{Introdução}

Configurado como um conjunto de saberes e práticas, partejar é um ofício tão antigo quanto a própria humanidade (LARGURA1998, apud MAIA, 2013, p.27) e majoritariamente uma atividade feminina, as chamadas parteiras tradicionais que atuam ou atuaram em lugares longínquos do Brasil, especialmente na zona rural. Constata-se que " historicamente as mulheres cuidaram das mulheres na hora do parto, trocaram conhecimentos sobre a gravidez, parto e pós-parto, assim como sempre fizeram com outros aspectos de sua vida cotidiana." MAIA (2013, p. 27).

Nas comunidades rurais, o processo de nascimento em domicílio se apresenta como uma experiência tecida em uma rede de múltiplos significados, tanto para as parteiras tradicionais como para as parturientes e familiares. No entanto, esta tarefa tem se reconfigurado nos últimos tempos mediante as novas demandas socioculturais, decorrendo em algumas regiões no esquecimento, que acaba por recair também no abandono à representatividade das parteiras.

O lócus da pesquisa pertence a zona rural do município de Wenceslau Guimarães, uma cidade com população estimada em 22.445 habitantes conforme dados do Instituto Brasileiro de Geografia e Estatística - IBGE 2016, fica localizado na mesorregião do Baixo Sul baiano a $290 \mathrm{~km}$ da capital Salvador.

$\mathrm{O}$ ato de partejar destas mulheres foi por mais de duas décadas importante para a região em tempos de dificuldades financeiras e de acesso à cidade, desenvolvendo-se em vários âmbitos na vida da gestante, desde o processo de gestação, parto e pós-parto. Com isso, 
criavam laços afetivos com as famílias, sendo chamadas de "mãe" pelas crianças que elas trouxeram à vida.

Estas mulheres não recebiam nenhum tipo de pagamento em dinheiro pelo seu trabalho a não ser por meio de presentes, desde um corte de pano a um animal de criação doméstico como porco e galinhas. Fato é que elas eram muito respeitadas por todos, lhe rendendo obediência e reverência em tempos de festejos como rezas e a quaresma.

Com o passar dos anos, o acesso à cidade melhorou, fazendo com que as parturientes se deslocassem em busca de um atendimento hospitalar e aos poucos o trabalho destas mulheres foi caindo em "desuso", e consequentemente, esquecido.

Perante a fluidez na Pós-modernidade, as relações entre gerações também têm se tornado por demais efêmeras, isto diminui a significação de tempo, resultando no esquecimento dos que vieram antes de nós. Bauman (2009) aponta que os sujeitos "mudam num tempo mais curto do que aquele necessário para a consolidação, em hábitos e rotinas, das formas de agir" (BAUMAN, 2009, p. 7). Isto significa dizer que não dá tempo para que as pessoas parem para escutar os mais velhos, como se o passado fosse um tempo qualquer sem ter nenhuma relação com o presente.

As diferenças de idades geram normas de comportamento e muitas destas normas é a naturalização do esquecimento e, por conseguinte, a invisibilidade dos mais velhos. É nessa ótica que refletimos o tempo presente das parteiras, uma interface da velhice.

Com o advento das novas tecnologias, os saberes das pessoas "comuns" foram sendo esquecidos, e substituídos pelo saber acadêmico institucionalizado. Diz Boaventura de Sousa Santos (1995) que "a ciência é um conhecimento discursivo, cúmplice de outros conhecimentos discursivos, literários nomeadamente (SANTOS, 1995, p. 332)”. Para Santos, os outros saberes têm sido deixados no esquecimento para dá ênfase ao elaborados pelas instituições acadêmicas.

Mediante o que aponta Santos (1995), os saberes de uma parteira não deve ser simplesmente esquecido, deixado para trás, visto que o conhecimento adquirido por estas pessoas não é menos válido aos que tem formação formal. Ao contrário, precisamos compreender o mundo pós-moderno como um lugar propício a ecologia de saberes, visto não ser possível uma teoria geral e nem unilateral. Sobre isso, Santos define que:

Não se trata de "descredibilizar" as ciências nem de um fundamentalismo essencialista "anticiência"; como cientistas sociais, não podemos fazer isso. O que vamos tentar fazer é um uso contrahegemônico da ciência hegemônica. Ou seja, a possibilidade de que a ciência entre não como monocultura mas como parte de uma ecologia mais ampla de saberes, em que o saber científico possa dialogar com o 
saber laico, com o saber popular, com o saber dos indígenas, com o saber das populações urbanas marginais, com o saber camponês. Isso não significa que tudo vale o mesmo. Discutiremos isso com o tempo. Somos contra as hierarquias abstratas de conhecimento, das monoculturas que dizem, por princípio, "a ciência é a única, não há outros saberes" (SANTOS, 2007, p. 32).

Pensando a partir das provocações de Boaventura Sousa Santos (2002), especialmente ao que tange os saberes populares e a pós-modernidade, necessitamos ampliar o olhar para a sociologia das ausências para oportunizar a visibilidade de sujeitos que estão no dia-a-dia fazendo as coisas acontecerem nos bastidores das dificuldades cotidianas, visto ser " $\mathrm{O}$ objetivo da sociologia das ausências é transformar objetos impossíveis em possíveis, objetos ausentes em presentes" (SANTOS, 2004, p. 21).

A partir do discutido em a Sociologia das ausências, Santos (2004) aponta a Sociologia das emergências como possibilidade de "identificar e ampliar os sinais de possíveis experiências futuras, sinais inscritos em tendências e latências que são ativamente ignoradas por essa racionalidade e por esse saber" (SANTOS, 2004, p. 30).

Mediante o exposto, esta pesquisa se faz relevante por considerá-la importante ao que concerne ao fato da (in) visibilidade de parteiras que dedicaram suas vidas em prol do ofício de partejar e, assim atender as outras mulheres no momento do parto na região sul da Bahia. A investigação objetiva ouvir o que estas mulheres, hoje idosas, têm a dizer sobre suas experiências, seus legados e, sobretudo, entender seus sentimentos com o "esquecimento" que vivenciam sobre si, no contexto contemporâneo.

\section{O percurso metodológico}

A pesquisa traz como sujeitos duas mulheres parteiras idosas moradoras de comunidades adjacentes dos territórios remanescentes quilombolas de Nova Esperança, no município de Wenceslau Guimarães-Bahia. É importante ressaltar que existem outras parteiras, mas para este artigo optou-se por realizar a entrevista apenas como duas delas. Essa restrição se deu pela observação nas visitas contínuas à região e do contato direto com as pessoas do lugar no qual foi possível conceber que as escolhidas ocupam lugar de destaque no imaginário coletivo como "mães de pegação" de muita gente.

O contato com elas se deu de forma direta, pois, já havia uma relação com as mesmas por ser a pesquisadora oriunda do lugar. Ao convidá-las a participar deste trabalho, demonstraram disponibilidade em colaborar. Estas duas mulheres são proprietárias de terras, viúvas, mães, exerceram atividades domésticas, na agricultora, além da atividade de partejar. 
Suas idades são de 86 e 95 anos. Atualmente, estão aposentadas. Uma é semialfabetizada e a outra analfabeta.

Para entender o objetivo proposto, o método utilizado é o narrativo de natureza qualitativo-explicativa, usando como técnica a História Oral de Vida com entrevistas abertas. O método Narrativo se torna importante neste tipo de pesquisa porque nos permite compreender as estórias contadas pelos sujeitos entrevistados sobre seus conflitos, suas conquistas e também seus dilemas, pois "Não há experiência humana que não possa ser expressa na forma de uma narrativa" (BAUER; JOVCHELOVITCH, 2002, p. 91). Este método possibilita articulações com outras narrativas e vozes, enveredando para uma abordagem histórica e interpretativa das estórias contadas e entrelaçadas com outras estórias. Configura-se também por ser uma narrativa livre que o sujeito constrói de si mesmo recontando conjuntamente seus saberes e suas culturas. Desse modo, "recontar se torna profetizar" (BRUNER, 1986, p. 153).

O método narrativo é, portanto, relevante ao que esta pesquisa se propõe, por permitir ouvir a voz de sujeitos com experiências e vivências a narrar - até então invisibilizadaspossibilitando alargar a visão sobre o indivíduo em sua totalidade e contexto.

Classificado como pertinente à pesquisa qualitativa, o seu caráter explicativo não é só por seu uso exacerbado nas ciências sociais, mas por vir carregado de subjetividades e autocrítica, o que é inerente à pesquisa proposta que envolve pessoas e processos. Por isso, o método narrativo, procurará compreender os fenômenos estudados sob o olhar do colaborador/a. Para Arlinda Schmidt Godoy (995):

A pesquisa qualitativa não procura enumerar e/ou medir os eventos estudados, nem emprega instrumental estatístico na análise dos dados, envolve a obtenção de dados descritivos sobre pessoas, lugares e processos interativos pelo contato direto do pesquisador com a situação estudada, procurando compreender os fenômenos segundo a perspectiva dos sujeitos, ou seja, dos participantes da situação em estudo (GODOY, 1995, p.58).

Por isso, a pesquisa qualitativa é o caminho do pensamento a ser seguido conforme Minayo (2002, p.18), pois os permite entender um problema social e humano em contextos específicos.

A fim de obter as informações pretendidas utilizam-se as narrativas dos sujeitos através da técnica da História oral. Conforme explicita Meihy (2002, p.13), “a história oral é um recurso moderno usado para a elaboração de documentos, arquivamento e estudos referentes à vida social de pessoas" podendo ser realizada a partir da entrevista 
semiestruturada. Essa técnicaprivilegia a realização de entrevistas com pessoas que participaram de, ou testemunharam acontecimentos, conjunturas, visões de mundo, como forma de se aproximar do objeto de estudo conforme discute Verena Alberti, 1990.

As entrevistas aconteceram nas residências das colaboradoras em dia e horário previamente combinados, em um local da casa no qual as mesmas se sentiram mais à vontade. Cada entrevista durou aproximadamente duas horas, incluindo as pausas e intervalos. A primeira a participar foi Dona Anastácia Maria de Jesus e posteriormente Dona Jardilina Licomédia de Jesus.

Na História Oral de vida podemos direcionar a entrevista com perguntas disparadoras. Nesta pesquisa, a entrevista foi desenvolvida a partir de duas perguntas: Como a senhora se tornou parteira? Aqui na região a senhora tem um grande respeito pelo trabalho que exerceu. Como é, atualmente, o tratamento das pessoas para com a senhora?

O passo seguinte foi o de transformação do texto gravado para o escrito e nisto seguiuse as seguintes etapas: transcrição, textualização, transcriação e análise final das histórias. Através da Transcrição realizamos escuta repetida do material gravado e registramos de forma fiel as falas das colaboradoras. Após esta etapa, fizemos textualização, passo no qual as perguntas foram suprimidas dando um caráter narrativo aos relatos. Nessa fase é onde retiramos o tema. Em seguida realizamos a transcriação, quando aconteceu a "alma" do texto. Todos os eventos, sentimentos, respiração, pausas, silêncios e pontuações foram colocados afim de mostrar sensivelmente a atmosfera da entrevista.

Os nomes das colaboradoras foram revelados, pois as mesmas desejam que as suas histórias sejam contadas e assim não caiam no esquecimento mesmo após a sua morte. Elas querem ser lembradas e o nome é parte importante para a permanência da memória. Assim, além de terem seus nomes revelados, ao longo das discussões serão tratadas pelos codinomes de tratamento com os quais elas são chamadas por todos que as conhecem, "Mãe Ana" de 96 anos e "Mãe Jarde" com 85 anos.

Após realização das entrevistas, os dados foram analisados sob a luz dos teóricos que discutem sobre as subjetividades do sujeito idoso, da liquidez da pós-modernidade e seus impactos na memória identitária, de gênero, na perspectiva das interseccionalidades e ainda sobre os mal-estares e valores culturais e intrapsíquicos da sociedade contemporânea. Para fundamentar esta pesquisa, será necessário debruçar-se em teóricos como: Marcuse (1975); Pollak (1989);Bauman( 1997); Scott (1999); Hall (2000); Freud (2011); GrinDebert (2004) Yuval Harari ( 2016), dentre outros. 


\section{Desenvolvimento}

Ao longo da história, as parteiras exerceram funções, podendo ser: acompanhamento das gestantes, escolhas das ama-de-leite, acompanhante de meninas aos exames médicos para verificar a virgindade e orientação para o cuidado do bebê para evitar a mortalidade infantil. No Dicionário Online de Português (2017), parteira significa "Mulher cuja profissão é assistir os partos, ajudar as parturientes, obstetriz, comadre. "Com uma explicação mais para o âmbito profissional o Dicionário Online Michaelis (2017), define parteira como "Mulher que não é formada em medicina, que assiste parturientes nos trabalhos de parto; comadre, madama, madame, obstetriz".

Os dicionários visitados trazem definições de certa forma simplificadora acerca do papel exercido por estas mulheres em diversos lugares do país, visto que na sua essência partejar era servir a outrem, mesmo sem o conhecimento científico. Os sinônimos apresentados, às vezes apresentam significado para além dos descritos pelos dicionários. Os termos madame e comadre dimensionam o grau de importância que estas mulheres representam para seus lugares de atuação, por serem assim tratadas pelas pessoas da região.

Diante do exposto, abordar sobre a história de vida das parteiras da região da Comunidade quilombola de Nova Esperança em tempos de mudanças de hábitos próprios das culturas pós-modernas e das melhores condições de vida e acesso à cidade e que, por conseguinte colaboram para o esquecimento destas, se torna um caminho possível para se repensar o olhar para o outro e por isto a história de vida de Dona Anastácia Maria de Jesus, 95 anos, ou simplesmente "Comadre Ana" ou "Mãe Ana” e de Dona Jardilina Licomédia dos Santos, 86 anos, conhecida como "Mãe Jarde" é preponderante pela importância que tiveram na história de tantas outras vidas e também visibilizar os mais velhos que por ora se encontram em esquecimento.

Em tempos pós-modernos, há uma predisposição social para a supervalorização ao fluido, jovem, rápido e com isto aquilo ou aqueles que não estão dentro desta lógica tendem a cair em ostracismo e esquecimento, no qual “... cada um ingressa num mundo 'pré-fabricado', em que certas coisas são importantes e outras não o são; em que as conveniências estabelecidas trazem certas coisas para a luz e deixam outras na sombra "(BAUMAN, 1998, p.17)".

Nesse sentido, Bauman (1998) aponta para uma realidade contemporânea que é a fluidez e depreciação das coisas e das pessoas em detrimento de algo mais aprazível e no 
contexto do que estamos discutindo, é muito comum a forma em que tudo que remeta ao antigo, seja desqualificado e, por conseguinte desvalorizado. No caso do ato de partejar, na roça, é tido como sinônimo de atraso e de irresponsabilidade, o que favorece para o aviltamento e ostracismo das mulheres parteiras, hoje idosas.

A historiografia oficial negou ou invisibilizou as mulheres. Elas foram por muito tempo omitido por esta historiografia que exaltava os homens, visto ser ela (História), escrita por homens e para homens, resultando em uma história em que a mulher era sempre estereotipada e tida como um sujeito histórico marginal. Isto contribuiu para fomentar uma sociedade baseada na diferença entre os sexos biológicos no qual o homem era supremo. Nesse contexto, a mulher mesmo presente na história torna-se invisível.

As mulheres foram, durante muito tempo, deixadas na sombra da História. O desenvolvimento da Antropologia e a ênfase dada à família, a afirmação da História das "Mentalidades", mais atenta ao quotidiano, ao privado e ao individual, contribuíram para as fazer sair dessa sombra. E mais ainda o movimento das próprias mulheres e as interrogações que suscitou. "Donde vimos? Para onde vamos?", pensavam elas; e dentro e fora das Universidades levaram a cabo investigações para encontrarem os vestígios das suas antepassadas e, sobretudo, para compreenderem as raízes da dominação que suportavam e as relações entre os sexos através do espaço e do tempo (DUBY, Georges e PERROT, Michelle. (orgs.)1995,7).

E neste deixar as sombras da História, a mulher enquanto profissional foi também esquecida e ou negada. Entretanto, elas sempre exerceram trabalhos para além dos domésticos, mas só a partir do século XIX é que a mulher vai começar a aparecer enquanto profissional, mesmo sendo ainda um trabalho idealizado a partir da concepção da fragilidade do gênero feminino.

Importante lembrar que a Idade Média europeia, um mundo teocrático. Qualquer transgressão à fé entendia-se também por transgressão política. Isto, mais precisamente a partir do fim do século XIII até metade século XVIII, quando houve os Tribunais da Inquisição No período, ocorreu o fenômeno intitulado de "Caça às bruxas" ${ }^{2}$, no qual segundo Muraro (2002), a maioria das vítimas era mulheres, cerca de $90 \%$. Segundo a autora em um

\footnotetext{
${ }^{2}$ No contexto histórico da Idade Média, bruxas eram as parteiras, as enfermeiras e as assistentes. Conheciam e entendiam sobre o emprego de plantas medicinais para curar enfermidades e epidemias nas comunidades em que viviam e, consequentemente, eram portadoras de um elevado poder social. Estas mulheres eram, muitas vezes, a única possibilidade de atendimento médico para mulheres e pessoas pobres. Elas foram por um longo período médicas sem título. Aprendiam o ofício umas com as outras e passavam esse conhecimento para suas filhas, vizinhas e amigas. [...] Além disso, o fato dessas mulheres usarem seus conhecimentos para a cura de doenças e epidemias ocorridas em seus povoados acabou despertando a ira da instituição médica masculina em ascensão, que viu na Inquisição um bom método de eliminar as suas concorrentes econômicas, aliando-se a ela (ANGELIN, n.d. 2005).
} 
único dia chegavam a executar centenas delas "Novecentas bruxas foram executadas num único ano na área de Wertzberg, e cerca de mil na diocese de Como. Em Toulouse, quatrocentas foram assassinadas num único dia" (MURARO, 1993, p. 7). Salientamos que as mulheres que a maioria das mulheres consideradas bruxas eram as que praticavam a medicina popular.

No séc. XIX abriram-se oportunidades profissionais para a mulher da classe média, um grupo relativamente novo na força do trabalho. Moças da classe média tornavam-se professoras, enfermeiras e assistentes sociais.

Este adendo à historiografia serve para compreendermos, mesmo que superficialmente, o construto da mulher enquanto profissional ao longo do tempo, mas também para percebermos que à medida que avançamos nas conquistas sociais, ao que tange as questões de gênero e classe, ainda temos muito para discutir e avançar, pois o trabalho das mulheres sem posses, sem instrução acadêmica permanece na invisibilidade, como é o caso das mulheres participantes desta pesquisa.

Ao que concerne à oposição entre as técnicas antigas e modernas ressaltamos que isto foi construído ao longo da história. No Brasil isto foi realçado a partir da reforma Pombalina que sob a ótica progressista e o ideário de civilização eurocentrada, implanta no país pela famigerada "Reforma pombalina" através do alvará de 28 de junho de 1759, que pôs fim ao modelo educacional instituído pelos padres jesuítas desde o início da colonização e inicia o modelo já aplicado na sede da Coroa portuguesa.

Seguindo os ideais iluministas, o Marques de Pombal queria uma educação no qual o povo fosse instrumentalizado para atender as exigências de uma sociedade em transformação, sobretudo, para a arregimentação dos poderes do estado. Suas ideias contemplavam o liberalismo e a razão para as quais "criou as aulas régias ou avulsas de Latim, Grego, Filosofia e Retórica, que deveriam suprir as disciplinas antes oferecidas nos extintos colégios jesuítas" (AMARAL e SECO, 2002, p. 06).

Entendendo que as mudanças não ocorrem abruptamente, mas como um processo construído a partir de projetos políticos e ideológicos, a substituição progressiva das técnicas do partejar tem íntima relação com a cultura da modernização imposta com a reforma pombalina. Nesse interim, quando se muda se as técnicas, naturalmente, esquecem-se os sujeitos envolvidos no processo, resultando em rejeição a realidade vivida com foco na realidade a ser alcançada. Nesse caso, a modernização. Sobre isto, Palharini (2018), assevera que: 
O instrumental tecnológico que começava a ser desenvolvido, pertencente exclusivamente ao domínio do cirurgião, conferia a fama de eficácia e domínio pelos homens sobre um evento do campo feminino. O fórceps, por exemplo, teve um papel histórico essencial para a aceitação do homem na cena do parto e para a marginalização das parteiras. $\mathrm{O}$ uso desse instrumental técnico, que garantia maior "sucesso" nos partos difíceis, contribuiu para a ideia do cirurgião como tendo maior controle sobre o parto, reforçada pela resistência das parteiras em relação ao uso do instrumento (PALHARINI, 2018, p. 1041).

Importante ressaltar a expressão "parteiras idosas", porque esta é outra concepção a ser pensada, quando se trata do esquecimento deste grupo social, marcados pelos preconceitos a velhice nas sociedades modernas, que abandonam os velhos a uma existência sem significado" (DEBERT, 2004, p. 17). Ou seja, são dois marcadores que as sociedades contemporâneas tendem a colocar de lado esquecendo-se de sua importância não só pelas contribuições de outrora, mas para a manutenção de suas próprias histórias.

Para Harari (2016), as sociedades contemporâneas necessitam de esse repensar e de redescobrir o outro, o mais velho, o mais experiente e desse modo nos tornarmos humanos mais sensíveis pela escuta e assim aprender com estes ao “(...) pensar na diversidade de respostas que os mais velhos são capazes de oferecer ante as mudanças ocorridas na sociedade contemporânea" (DEBERT, 2004, p. 92). E no caso destas mulheres idosas, ao nos permitirmos à escuta, sem dúvida temos muito para aprender, pois [...] O conhecimento é interconhecimento, é reconhecimento, é auto-conhecimento" (Santos, 2005, p. 157).

Os sujeitos historicamente esquecidos, a exemplos das parteiras, são partes do conhecimento guardado a espera de quem queira ouvir e aprender. São estes grupos silenciados detentores de parte da chamada ecologia dos saberes, proposta por Santos, (2005). Ao debruçarmos interesses por esses conhecimentos mobilizamo-nos para não fícarmos estáticos apenas aos saberes do nosso próprio tempo porque a "História não tolera o vazio " (HARARI, 2016, p. 29).

A pós-modernidade é também presenteísta no sentido de que por mais líquidos que sejam os encontros e a validade das coisas, convergem na direção das relações complexas nas quais práticas antigas e da contemporaneidade coexistem seja nas referências individuais, seja nas representações coletivas, seja por reconhecimento de pertencimento ou por sociabilidades adquiridas. Assim é o ato de partejar. Por mais moderna que sejam as técnicas médicas, as parteiras continuam existindo, e relacionando-se com as pessoas de seu lugar, construindo laços e reverberando seus saberes na cotidianidade da viva vivida. 
Ao tratarmos do tempo, seja o vivido ou o momento presente, outra categoria merece ser analisada: o esquecimento. Ele é recorrente nos discursos proferidos e constituídos na memória acentuado pelos sujeitos, a fim de desempenhar as funções positivas da memória comum. A esse respeito Pollak (1989) profere que:

A memória, essa operação coletiva dos acontecimentos e das interpretações do passado que se quer salvaguardar, se integra. Como vimos, em tentativas mais ou menos conscientes de definir e de reforçar sentimentos de pertencimento e fronteiras sociais entre coletividades de tamanhos diferentes (POLLAK, 1989, p 9).

O esquecimento é confinado no âmago de cada uma, provocando silenciamentos resultando na não permanência de fatos importantes para a coletividade. Entretanto, nesse mesmo silêncio há compenetração de lembranças vivas do sujeito, podendo transmitir acontecimentos dissidentes. Nesse sentido, esquecimento é o modo operante da memória que seleciona o que dizer e o que vai ficar na memória subterrânea.

A categoria de gênero também é enfocada, neste estudo, por ser a atividade de partejar uma atuação majoritariamente feminina configurada por questões éticas, culturais e de representação simbólica, a depender do local e do seu construto histórico. Atemos-nos a questão de gênero enquanto categoria social da feminização dada ao ato de partejar por ser uma atividade que envolve valores éticos e simbólicos em torno do parto.

Por isso, gênero comporta as discussões que envolvem as histórias de vida das parteiras que aqui nos propusemos conhecer, pois o partejar, para elas, é uma atividade que requer delicadeza, renúncia e dedicação, adjetivos geralmente atribuídos às mulheres.

É possível também, analisá-las na perspectiva da interseccionalidade de gênero pois, conforme aponta Debert (2004, p. 140) “As mulheres na velhice experimentariam uma situação de dupla vulnerabilidade, com o peso somado de dois tipos de discriminação - como mulher e como idosa".Gênero nesse caso "é então um conceito associado ao estudo de coisas relativas às mulheres." Salienta Scott (1995, p.76). A interseccionalidade, neste estudo, debruça-se sobre as opressões de raça, classe, gênero. Essas parteiras perpassam por esse caminho, sendo elas mulheres negras e pobres. Sobre o lugar da mulher negra, a filósofa Djamila Ribeiro (20017) argumenta que "as mulheres negras ocupam um espaço vazio, um espaço que se sobrepõe às margens da raça e do gênero, o chamado terceiro espaço, um tipo de vácuo de apagamento e contradição em um mundo polarizado em negros de um lado e mulheres de outro" (RIBEIRO, 2017, p. 38).

Abordar gênero, aqui nos permite compreender as relações complexas construídas socialmente em volta dessas mulheres parteira, majoritariamente negra, que foram 
indispensáveis na vida de tanta gente e ao mesmo tempo ignoradas e despercebidas com o passar do tempo.

As questões de gênero enredam pela identidade definindo padrões e também minúcias até porque os sujeitos são construídos pelas diferenças, que os tornam únicos em uma construção que envolve valores e símbolos no qual numa movimentação em contínuo, as identidades também se reconfiguram diante outras identidades possíveis no mundo pósmoderno.

Para Hall (2014, p. 9), "as identidades modernas estão sendo "descentradas”. E pensar a identidade na perspectiva da mudança cultural de uma atividade a princípio em caducidade que é o partejar é compreender que outras possibilidades fragmentam a identidade das figuras envolvidas até então tidas como heroínas e isto resulta na chamada de "crise de identidades" discutida por Hall (2014).

A identidade é formada na "interação" entre o "eu" e a sociedade. O sujeito ainda tem um núcleo ou essência interior que é o "eu real", mas esse é formado e modificado num diálogo contínuo com os mundos culturais "exteriores" e as identidades que esses mundos oferecem (HALL, 2014, p.11).

Tudo isto ocorre dentro do contexto da pós-modernidade no qual as instantaneidades das coisas fazem com que as identidades tão fixas, na modernidade, e entrem em declínio, pois a sociedade está em constante mudança.

Partindo das análises supracitadas podemos considerar que o ofício de partejar simboliza um construto social e intrapsíquico na nova conjuntura de sociedade, na qual os avanços tecnológicos e higienistas impulsionam sua desvalorização por não haver um respaldo oficial de sua importância para os lugares longínquos e isto perpassa por esquecimentos, reconhecimentos, pertencimentos e identidades.

Nesta região especificamente o partejar vem perdendo sua legitimidade embora no recontar da história sejam notórios os saberes e valores que foram compartilhados coletivamente. As históriasde vida aqui partilhadas são de mulheres que antes do ofício de partejar são domésticas, mães, agricultoras, rezadeiras, profundas conhecedoras de ervas e saberes que na fluidez pós-moderna tornam-se obsoletas. No contexto in loco "ser parteira" é:

Um dom de Deus. Nós num escolhe. É escolhida. Nós num nasce sabendo não. A parteira aprende toda vez qui faz um parto. Toda vez aprende mais. Se os povo subesse mermo o que é uma parteira tinha mais respeito. Salvamos muitas vidas. A gente fazia isso como missão. Fazer o bem né? Mais hoje acho que num é mais importante não (MÃE JARDE, 2017). 
Esse depoimento revela a importância do ato de partejar e o quanto os valores embutidos nele estão na memória de quem viveu o auge da atividade e a consciência do quanto estas mulheres são importantes, embora haja uma desvalorização no tempo presente.

As duas mulheres participantes da pesquisa constroem uma teia de significados ao falar de si e da atividade do partejar. Ambas, convergem em pontos que tratam da valorização e reconhecimento das suas contribuições para a sociedade. A seção que segue nos permite conhecê-las e compreendermos a dimensão traçada por cada uma.

\subsection{O revelar das parteiras}

MÃE ANA - tem 95 anos, nascida em Curralinho, município de Jequié Bahia, foi morar na região após se casar com Sr. Bernardo Rocha. Mãe biológica de cinco filhos e de "pegação" teve mais de duzentos. Agricultora, hoje viúva, aposentada, tem casa na cidade de Jaguaquara, Bahia, mas prefere ficar na roça porque, segundo ela, apenas comia e dormia e na roça não, continua fazendo o que gosta que é arrancar mandioca, torrar farinha, fazer beijú e visitar os doentes. Atendia chamados a qualquer hora do dia e da noite, andou muitas léguas e ficava dias fora de casa. Assim lembra:

Eu tinha mais ou menos vinte anos quando eu comecei. Eu já tinha os meus filho tudo. Eu queria saber dos filho que Deus me deu licença que eu segurei. Foi mais de duzentos que me alembro. Deus deu licença que eu segurei (MÃE ANA, 2017).

MÃE JARDE - Hoje, com 86 anos, nascida na comunidade, casou-se com o Sr. Siriaco dos Santos, teve um filho biológico e mais de 100 de "pegação". Começou a fazer parto aos 40 anos de idade por acaso e gostou. Não tinha hora para ser chamada e nunca negou um pedido. Andava muitos quilômetros, seja debaixo de chuva ou sol. Fazia porque acreditava ser um chamado divino. Aprendeu sozinha. Hoje, doente, vive sentada na varanda de sua casa à beira da estrada e diz com saudosismo:

Eu gostava demais, (...) eu gostava de sair. Toda vez que eu fazia, a pessoa aprende mais. Tinha gente que eu já acompanhava já nos primeiro meses. Aquelas mulher de gravidez difícil. Tinha vez que eu ficava até três dia. (...)Só tive um filho. Mais dei vida a um bucado. Tenho um bucado de gente aí que me chama de mãe (MÃE JARDE, 2017).

\subsection{Análise de resultados}


Pelo prisma da narrativa-explicativa, o depoimento de cada colaboradora foi analisado buscando apresentar a forma como estas mulheres compreendem ou percebem a importância de suas atividades, suas representatividades e de como vêem a atividade de partejar, no contexto contemporâneo.As narrativas de cada uma nos permitem a compreensão das histórias de vida das parteiras na percepção de si e da tarefa exercida.

De início, é possível dizer que em ambas as narrativas as colaboradoras aceitaram a missão por entenderem ser um legado divino e, por isso, irrecusável. As mesmas afirmam não ter sido uma escolha pessoal e, sim, uma emergência diante das necessidades da comunidade resultantes das condições precárias de vida naquela época. Os serviços de saúde eram precários e, ou inexistentes e ainda havia obstáculos geográficos, pois, a região fica distante da sua sede e de outras cidades vizinhas, contando ainda com as dificuldades de locomoção e transportes. Naquele contexto, poucas pessoas tinham carro e nem todos estavam disponíveis a servir.Para "Mãe Ana", o partejar é um ofício que recupera a dignidade da mulher que naquele momento está em angústia e risco de vida

De primeirão quando num tinha dotô era cinco seis dia as mulé sofreno. Mais graça a deus ninguém nunca morreu nas minha mão. Tudo foi feliz cum seus fim (...) Eu andava menino. Um dia fui daqui lá em Dolivá. Era de notão. Meus filhos fechava as portas. E eu viajava. Já andava com a sacola arrumada. Colocava um vestido e viajava viaja... carregava óleo de ormenda,foia de ostra, tudo práajudá (MÃE ANA, 2017).

As parteiras têm papel fundante no momento do parto, por saberem conduzi-lo utilizando-se dos saberes. Este fato, tornava a sua figura muito respeitada por todos. Outra coisa a considerar é a satisfação causada pelo sucesso do parto.

Harari (2016, p.29) argumenta que "somos dotados da capacidade de fazer as coisas melhorarem e de reduzir ainda mais a incidência do sofrimento. Porém, o reconhecimento da magnitude de nossas conquistas traz consigo outra mensagem ". Mensagem esta que está nas representações simbólicas de respeito e reconhecimento social, no caso do ato de partejar, praticado por elas.

"Mãe Jarde" relata que "Os parto era tudo de noite, (risos) o povo vinha atras de mim. Num tinha hora não. Corquer hora. Dexava marido e filho. E iasimbora. Ficava o tanto de dia qui precisasse “. O mesmo é confirmado por Mãe Ana quando diz:

Era quarquer hora da noite. De madrugada. Ficava até 8 dias na casa da mulher. Eu lembro da mulher de cumpadepedo Piroca. CumpadePedo morreu? Ainda é vivo? 
Nem sei. Lá eu fique dias e dias. Hoje nem uma visita vem me fazer. (...). Me chamava era meia- noitevéa (velha) (MÃE ANA, 2017).

Nas duas narrativas fica evidenciado que o ofício delas não era fácil, por isso mesmo, foram necessários sacrifícios para conciliar seus afazeres domésticos com o ofício de partejar. O que indica a presença das interseccionalidade de gênero, pois eram mulheres, mães, esposas, dona-de-casa e parteiras.

Um papel extremamente complexo na divisão do trabalho cotidiano, pois o partejar na região era exclusivamente feminino, aos homens/maridos, cabiam ajudar a segurar a mulher, caso fosse necessário.

Entretanto, as duas colaboradoras afirmaram que mesmo tendo essa missão, nunca deixaram de cuidar da casa e dos filhos e muitas vezes trabalhavam no roçado. "Mae Ana", diz que nunca houve isso de dividir os trabalhos, se fazia quando dava. O marido só tomava com dos filhos quando tinha de sair apressadamente e por vezes, ficar vários dias fora de casa. Já "Mãe Jarde" relata que " como todo mundo se conhecia, as minina que ia cresceno por ali, as mãe mandava para cuidar da casa, oiá os bicho inté eu chegar”.

O partejar, conforme o objetivo deste trabalho está em processo de esquecimento diante das novas demandas contemporâneas que desvelam em avanço no trato da saúde básica e do próprio desenvolvimento econômico e tecnológico. E isto é acentuado nas narrativas das colaboradoras, quando ambas ressaltam tanto o esquecimento do ofício, quanto demonstram preocupação com isto. Para "Mãe Ana":

Hoje ninguém quer aprender... tem gente qui tem inté medo. Mais acho qui tinha que saber, porque se chover dimais carro aqui num sai não. E aí? (...) Eu aprendi antigamente que a mãe é só um saco que carrega o menino nus nove mês. Qui mãe mermo é a que pega. Mais o pessoánum quer saber de nada de véio não. (risos) Tá tudo perdido. A desobediência é grande. As pessoa num quer aprendê não. Tem dela qui tem inté (MÃE ANA, 2017).

Neste mesmo ângulo, "Mãe Jarde” acentuao seguinte:

Sem parteira aqui vai fazer falta. Porque se uma mulher atacar de uma ora pra outra pra parir se num tiver quem ajude não pare. Vai fazer falta (...) Falta de respeito com os mais velho. Mais ninguém hoje em dia nun liga mais cum essas coisa não. Né não? Eu eu gostava de fazer. Tenho saudade. Sinto farta. Porque tem minino que é amarrado mermo. A mulé sofre. A parteira é muito importante minha filha. Porque quando a gente salva a vida de uma mulher e de uma criança, é uma alegria. (pausa longa) com os médico hoje, as pessoas nun quer aprender, mas é importante (assovio) porque é uma boa vontade importante (MÃE JARDE, 2017). 
As experiências vividas não dão significado apenas a nós mesmos. Elas assumem outros significados que perpassam representações culturais e, por conseguinte constroem identidades coletivas. O partejar destas mulheres por ora não está fazendo parte da dinâmica local, mas está no imaginário coletivo em um passado distante e por isto, resulta em certo esquecimento tanto do ofício quanto das representações envolvendo o nome, a função dessas mulheres parteiras.

Logo, o sentimento de ser esquecido pode atingir a identidade pessoal do sujeito e do grupo visto que somos uma sociedade em constante mudança. Bauman (1998, p. 38) consideraser o esquecimento um o "problema da identidade" não resolvido, fenômeno próprio da cultura pós-moderna.

Para driblar este apagamento necessitamos enaltecer as experiências antigas pois “A tradição é um meio de lidar com o tempo e o espaço, inserindo qualquer atividade ou experiência na continuidade do passado, presente e futuro, os quais, por sua vez, são estruturados por práticas sociais recorrentes ". (HALL, 2014, p.11 - 12).

Outra narrativa elencada pelas colaboradoras foi sobre a recepção dada a elas. Ambas se disseram esquecidas por parte da maioria das pessoas, mas cada uma denota um tipo de sentimento a esse respeito. Segundo "Mãe Ana":

\footnotetext{
Ninguém hoje respeita mais ninguém. Oxe! Tu tá pensando que ninguém se importa cum eu? Oxe nem dá bença. Só os minino de cumpadePedo de Bitu. Tudo me chama de Mãe Ana. Pra mim é uma alegria quando um vem me dá bença. Tem gente que sumiu nem sei se ainda é vivo. Eu queria muito que os minino que eu peguei viesse me visitar. (... ) Mas os povo hoje nun liga mais pra ninguém não... tem uns se pudesse nem bença as mãe de verdade dava mais, imagina a mãe que pegou. (...) Tudo que eu peguei nenhum morreu....... os pessoa num alembra de mim, mas nun fico triste não. Que cada um corra na sua mimora (memória)..... eu sou feliz. Cumpri minha missão....mas eu gostava se fosse lembrada.( emoção) Muitos me agradeceu, mas muito não agradeceu (MÃE ANA, 2017).
}

Para Mãe Ana o esquecimento de alguns a deixa triste, mas mostra tranquilidade ao demonstrar consciência da sua importância na vida de muita gente e ela ainda relata que gostaria de fazer uma lista com os nomes de todos que ela "pegou", ao revelar o seguinte desejo:

Eu queria pedir as menina para assentar num papé os minino que eu peguei. Isso sempre foi bom pra mim. Um dia vou comprar um "bichim" e mandar colocar num papé, mas esqueço, nunca me importei, nunca me alembrei. E eu ir dizendo, os que eu lembrar, para as meninas colocar os nome dos menino que eu segurei meu Pai, com Deus na minha frente (Mãe ANA, 2017). 
A reação de "Mãe Jarde" é de mais tristeza pelo esquecimento, até porque ela gostava de fazer parto. Para ela cada vida que ela trazia ao mundo era uma alegria. Ser esquecida, para ela,significa demonstração de ingratidão. Mas ela afirma ser feliz.

Hoje eu sou esquecida. Só quem vem aqui me ver é os minino de Otavo. Fico triste. $\mathrm{Eu}$ queria que viesse me ver, mas nun vem (emoção)(...) Eu acho bunito ser chamada de mãe. Fazer parto é bom... hoje eu moro aqui perto da estrada, os homem e a mulé (mulher) hoje tudo mãe, passa aí nem chega e nem pergunta Cuma eu tô (Mãe JARDE, 2017).

Existe uma coerência nas duas narrativas, no que diz respeito ao desejo de que gostariam de ser visitadas. Elas não desejam o vedetismo, nem tampouco reverências, querem simplesmente receber uma visita de vez em quando.

Podemos, então, perceber nas falas de cada parteira os fenômenos que as une, acerca de seus legados como: a ajuda ao próximo, a percepção de que salvaram vidas, as renuncias pessoais e do esquecimento sofrido. Este último associado ao sentimento de que há ingratidão por parte de algumas pessoas por elas ajudados. E isto tem uma profunda relação com a forma de se tratar a velhice e a definição do seu lugar social, embora DEBERT (2004, p. 57) aponte que na sociedade atual há "a promessa de que é possível escapar dos constrangimentos e dos estereótipos, das normas e dos padrões de comportamento baseados nas idades. (...) é preciso tempo para avaliar se essa promessa é uma ilusão ou uma esperança realistaa indicar mudanças libertárias".

Ainda sob a ótica do esquecimento, as parteiras revelam não lembrar exatamente quando começaram a fazer partos, mas têm a consciência que foi em um momento de grande importância, em situação de urgência, de acordo o que diz “Mãe Jarde “:”Eu nun lembro quando eu comecei, não. Sei não. Faz muito tempo. Só sei que foi depois dos vinte anos. Eu mermo assim, num pensei que eu ia fazer isso não. Mas a gente aprende (risos)" e"Mãe Ana", ao falar desse seu início, traz à memória nomes de pessoas importantes para ela:

Cuma comecei? (....) Tu sabequi eu nem sei? Peraí? Foios filho de cumade Maria... foi os que ela teve ai quem pegou tudo foi. Foi o depois de cumade Maria de cumpadePedo de Bitu qui comecei a pegar minino. Os de Nice tudo. Pegue três de decumade Maria de Rodrigue. Peguei três dela. Despois disso num parei mais. Só dispois de veia (velha) que eu disse: agora cansei! Pruquê a parteira conhecida num pode vim. Tavaduente. Foi cumade Jovem de Lenhada. (....) tu cunheceu? Ah! Era uma muié muito boa.Sarvou muita gente aqui. Ela que pegôos meu (MÃE ANA, 2017). 
As entrevistas revelam a seleção da nossa memória entre o que lembramos e o que desejamos não dizer. Ressaltamos também o retorno ao passado distante no qual pessoas são importantes porque na "reconstrução de si mesmo o indivíduo tende a definir seu lugar social e suas relações com os outros" (POLLAK, 1989, p.13). Ainda nesta fala, "Mãe Ana", ressalta ter deixado de partejar porque cansou e com isto, a mesma registra seu empoderamento ao desistir quando não mais se encontrava em condição para dar continuidade.

Partejar em tempos na contemporaneidade nas localidades adjacentes da Comunidade Quilombola Nova Esperança, no município de Wenceslau Guimarães, Estado da Bahia, está passando por uma "crise de identidade" (DEBERT, 2004, p.53) ao que tange sua permanência cultural, perpassando por tensões entre a tradição e a modernidade na representação simbólica das parteiras que colaboraram para este trabalho.

\section{Considerações}

Uma pesquisa que opta pelo caminho metodológico da narrativa e a técnica da História oral de vida não termina quando se encerra uma etapa institucional. Por isso,este estudo é um caminho aberto para outras análises, pois não há uma resposta pronta e o que nos propomos aqui foi discutir um processo e não encontrar repostas conclusivas. O artigo propõe a pensar as questões que envolvem a cultura do parto na zona rural, realizado pelas mãos de parteiras dentro do contexto da cultura contemporânea. E isto já é um caminho aberto para outras indagações, uma vez que o atual representa uma constante transformação sóciohistórica e cultural.

No entanto, ao que até aqui foi apurado, compreendemos que o partejar está entrando para o ostracismo, mediante as novas possibilidades inerentes ao presente, assim como ocorre o esquecimento da representatividade das colaboradoras. Embora sejam mulheres muito conhecidas na localidade, disseram se sentirem, sim, esquecidas e até de certo modo entendem que por parte da maioria assistidos por elas, há ingratidão por tudo que elas fizeram. As mesmas confirmam ser um trabalho sem remuneração e pelo qual recebiam presentes, mas disseram não gostar de recebê-los por entenderem ser um ofício, um dom divino. Estas mulheres se dizem felizes porque sabe que fizeram o bem a muita gente.

A questão de gênero é um marcador em se tratando da divisão clara da incumbência enquanto uma missão feminina e os encargos que a mesma trazia, pois tinham de administrar outras situações cotidianas como casa, filho, marido e o roçado por serem nos seus entendimentos tarefas sob suas responsabilidades. 
Sobre isto Flávia Biroli (2018) ressalta a construção hegemônica do patriarcado para o qual todas as atividades da casa e da família são atreladas como responsabilidade do sexo feminino. No caso das parteiras, elas tinham duplas jornadas de trabalho e com baixa ou nenhuma remuneração.

Sendo a contemporaneidade caracterizada pela sua liquidez em todos os âmbitos das relações humanas, as identidades também se movem e se refazem. Nesse sentido, as idosas e sujeitos desta pesquisa reinventam seus modos de ver o mundo moderno e, de certa forma, procuram interagir com a juventude e as maneiras desta compreender o mundo, uma vez que, enquanto há memória, existe vida e enquanto existir interação entre velhos e jovens haverá a tradição em um construto contínuo da identidade.

Em síntese, o trabalho aqui descrito revela a história de vida destas duas mulheres e a importância do partejar em tempos de outrora e do esquecimento do mesmo na pósmodernidade e a representatividade disto para a valorização de sujeitos e práticas que vão sendo esquecidas sem nenhuma preocupação com a manutenção e o tecer da memória. Por isto vozes e histórias de vidas subalternizadas precisam ocupar espaços merecidos para o reconhecimento do ofício de partejar por elas exercida.

Entendendo que todas as pessoas têm lugares de fala, ouvir e reproduzir o que disseram e ainda dizem estas mulheres é para além da produção acadêmica. É poder oportunizar para pensarmos o quanto ainda temos que aprender e o quanto à academia precisam estabelecer pontes com os grupos subalternizados e se abrir para a ecologia dos saberes existe fora de seu espaço, onde pensar lugar de fala é uma postura ética e de acesso ao direito de ser.

\section{Referências}

ALBERTI, V. História oral: a experiência do CPDOC. Rio de Janeiro: Contemporânea do Brasil, 1990.

AMARAL, Tania Conceição Iglesias. SECO, Ana Paula. Marquês de Pombal e a reforma educacional brasileira. Navegando na história da educação brasileira. Disponível em: www.histedbr.fe.unicamp.br/navegando/periodo_pombalino. Acesso em 29 de abril de 2019.

BAUMAN, Zygmunt, $O$ mal-estar na pós- modernidade. Tradução Mauro Gama, Claudia Martineli Gama. Rio de Janeiro. Jorge Zahar Editora, 1988.

, Zygmunt, Tempos líquidos / Zygmunt Bauman ; tradução Carlos Alberto Medeiros. - Rio de Janeiro : Jorge Zahar Ed., 2007. 
BAUER, M.; JOVCHELOVITCH, S. Entrevista Narrativa. In: BAUER, M.; GASKELL, G.. Pesquisa qualitativa com texto, imagem e som. Petrópolis: Vozes, 2002.

BIROLI, Flávia. Gênero e Desigualdades: limites da democracia no Brasil. 1. ed. São Paulo :Boitempo, 2018.

BRUNER, E. Ethnography as narrative. In: TURNER, V.; BRUNER, E. (Ed.). The anthropologyofexperience. Chicago: llinoisUniversity Press, 1986. p. 139-155.

DEBERT, G.G, A reinvenção da velhice. Editora: universidade de São Paulo.São Paulo, 2004.

DICIO. Dicionário Online de Português. Disponível em: https://www.dicio.com.br/parteira/s. Acesso em: 28 de abril de 2017.

DUBY, Georges; PERROT, Michelle (org.). Porto: Afrontamento, 1990.

PALHARINI, Luciana Aparecida. Gênero, história e medicalização do parto: a exposição "Mulheres e práticas de saúde". História, Ciências, Saúde - Manguinhos, Rio de Janeiro, v.25, n.4, out.-dez. 2018.

GODOY, A. S. Introdução à pesquisa qualitativa e suas possibilidades. In: Revista de Administração de Empresas. São Paulo 1995.

HALL,Stuart, A identidade na pós-modernidade. Stuart Hall; tradução de Tomaz Tadeu e Silva \& Guacira Lopes Louro. Rio de Janeiro: Lamparina, 2014.

HARARI, Y.N. Homo Deus: uma breve história do amanhã. Editora SCHWARCZ S.A. São Paulo, 2015.

LARGURA, M. A assistência ao parto no Brasil: aspectos espirituais, psicológicos, biológicos e sociais. São Paulo: 1998.

MAIA. Maia Luna. Com o poder de Deus nas mãos: concepções das parteiras acerca da vivência do parto numa perspectiva da espiritualidade. Dissertação de Mestrado. João Pessoa, 2013.

Disponível

em:

http://tede.biblioteca.ufpb.br/bitstream/tede/4208/1/ArquivoTotalLuna.pdf. Acesso em: 1 de maio de 2017.

MARCUSE, H, Eros e Civilização: uma Interpretação Filosófica do Pensamento de Freud. Tradução de Álvaro Cabral. ZAHAR EDITORES, RIO DE JANEIRO, 1976.

MEIHY, J.C.S.Bom. Manual de história oral. São Paulo: Loyola, 2002.

MINAYO, M. C. S. (2002). Ciência, técnica e arte: O desafio da pesquisa social. In M. C. S. Minayo, Pesquisa social: Teoria, método e criatividade. Petrópolis, RJ: Vozes.

MICHAELLIS. Dicionário Brasileiro da Língua Portuguesa. Editora Melhoramentos. Disponível em: http://michaelis.uol.com.br/busca?id=L1lwP. Acesso em 28 de abril de 2017. 
MURARO, Rose Marie. Malleusmaleficarum - o martelo das feiticeiras. Rio de Janeiro: Editora Rosa dos Tempos. Breve Introdução Histórica,1993.

RIBEIRO, Djamila. O que é lugar de fala? Belo Horizonte (MG): Letramento; Justificando, 2017

POLLAK, Michael. Memória, Esquecimento, Silêncio . ESTUDOS HISTÓRICOS - 1989.

SANTOS, Boaventura de Sousa. Pela mão de Alice: o social e o político na pósmodernidade. São Paulo: Cortez Editora, 1995.

Boaventura de Sousa. Renovar a teoria crítica e reinventar a emancipação social. São Paulo: Boitempo Editorial, 2007.

, Boaventura de Sousa. Para uma sociologia das ausências e uma sociologia das emergências, In: SANTOS, B.S. (org.), Conhecimento Prudente para uma Vida Decente. São Paulo: Cortez Editora, 2004.

SCOTT. Joan Wallach. "Gênero: uma categoria últil de análise histórica." Educação e realidade. Porto Alegre. Vol. 20. N². 1995. 